\title{
Oncological outcomes of patients with salivary gland cancer treated with surgery and postoperative intensity-modulated radiotherapy: a retrospective cohort study
}

\author{
Shoumei Zang ${ }^{1 \#}$, Meiqin Chen ${ }^{2 \#}$, Huijie Huang ${ }^{3}$, Xinli Zhu ${ }^{1}$, Xinke Li ${ }^{1}$, Danfang Yan $^{1}$, Senxiang Yan $^{1}$ \\ ${ }^{1}$ Department of Radiation Oncology, the First Affiliated Hospital, College of Medicine, Zhejiang University, Hangzhou, China; ${ }^{2}$ Department of \\ Radiation Oncology, Affiliated Jinhua Hospital, College of Medicine, Zhejiang University, Jinhua, China; ${ }^{3}$ Department of Radiation Oncology, Yili \\ Friendship Hospital, Yili, China
}

Contributions: (I) Conception and design: S Zang, M Chen, D Yan; (II) Administrative support: S Yan; (III) Provision of study materials or patients: X Zhu, X Li; (IV) Collection and assembly of data: S Zang, M Chen, H Huang; (V) Data analysis and interpretation: S Zang, D Yan, S Yan; (VI) Manuscript writing: All authors; (VII) Final approval of manuscript: All authors.

\#These authors contributed equally to this work.

Correspondence to: Danfang Yan; Senxiang Yan. Department of Radiation Oncology, the First Affiliated Hospital, College of Medicine, Zhejiang University, Hangzhou 310003, China. Email: danfang1116@163.com; yansenxiang@zju.edu.cn.

Background: Salivary gland cancer (SGC) is relatively rare and constitutes a variety of histological subtypes. Previously published studies of SGC patients suggest that postoperative radiation using conventional radiotherapy (RT) or 3-dimensional (3D) conformal radiotherapy may have led to suboptimal oncological outcomes.

Methods: We identified 60 patients with major SGC treated with surgery followed by postoperative intensity-modulated radiotherapy (IMRT). Data for overall survival (OS), progression-free survival (PFS), locoregional relapse-free survival (LRRFS), distant metastasis-free survival (DMFS), prognostic factors, and treatment-related toxicities were analyzed. Survival was analyzed using the Kaplan-Meier method and compared using the log-rank test.

Results: With a median follow-up of 55.5 months, based on Kaplan-Meier analyses, the OS and PFS rates for SGC patients at 3, 5, and 10 years were $90.7 \%, 85.1 \%$, and $85.1 \%$ and $80.1 \%, 72.7 \%$, and $63.1 \%$, respectively. The LRRFS and DMFS rates at 3, 5, and 10 years were $87.4 \%, 82.1 \%$, and $82.1 \%$ and $85.3 \%, 78.4 \%$, and $66.1 \%$, respectively. In multivariable analysis (MVA), the node stage (N stage) was an independent predictor of $\mathrm{PFS}[\mathrm{P}=0.047$; hazard ratio $(\mathrm{HR})=0.089]$. A positive margin was a significant prognostic factor for PFS $(\mathrm{P}=0.036$; $\mathrm{HR}=4.086)$, LRRFS $(\mathrm{P}=0.026 ; \mathrm{HR}=5.064)$, and $\mathrm{DMFS}(\mathrm{P}=0.011 ; \mathrm{HR}$ =6.367). Major nerve involvement was significantly correlated with $\mathrm{PFS}(\mathrm{P}=0.034 ; \mathrm{HR}=2.394)$ and DMFS $(\mathrm{P}=0.008 ; \mathrm{HR}=2.115)$. The interval from surgery to radiotherapy predicted $\mathrm{PFS}(\mathrm{P}=0.036 ; \mathrm{HR}=3.934)$ and DMFS $(\mathrm{P}=0.012 ; \mathrm{HR}=6.231)$. Adenoid cystic carcinoma (ACC) was the most common histology $(\mathrm{n}=21 ; 35 \%)$. For ACC, the 5-year OS, PFS, LRRFS, and DMFS were 100\%, 67.7\%, 76.2\%, and 90.2\%, respectively. The most common acute toxicities were mucositis and dermatitis, and xerostomia was the most common late adverse event. Lung metastasis was the most common pattern of distant failure.

Conclusions: $\mathrm{N}$ stage, positive margin, major nerve involvement, and interval from surgery to radiotherapy were important factors associated with PFS, LRRFS, and DMFS. Postoperative IMRT leads to improved survival for SGC patients, with acceptable toxicities. 
Keywords: Salivary gland cancer (SGC); intensity-modulated radiotherapy (IMRT); survival

Submitted Aug 22, 2021. Accepted for publication Jan 14, 2022.

doi: 10.21037/qims-21-836

View this article at: https://dx.doi.org/10.21037/qims-21-836

\section{Introduction}

Salivary gland cancer (SGC) constitutes a heterogeneous group of diseases, accounting for only $3-6 \%$ of all cases of head and neck cancer (1). Although its etiology remains unclear, the prognosis of SGC has improved thanks to combined treatments of surgery, postoperative radiotherapy (PORT), and chemotherapy. Retrospective reviews have shown that the prognosis of SGC depends on the histology, grade, and stage (2-4) of SGC. Other characteristics affecting prognosis include positive margin, extracapsular extension, and bone and perineural invasions (1).

Owing to differences in the number of patients enrolled in each study, pathological types, and treatment strategies, it is difficult to compare studies. Intensity-modulated radiotherapy (IMRT) has led to increased treatment accuracy and the possibility of delivering higher doses to the tumor region. This suggests that previous studies which have included patients who were irradiated using conventional radiotherapy (RT) or 3-dimensional conformal radiotherapy (3-DCRT) may have yielded lower locoregional control rates. We focused on postoperative IMRT, which was developed to improve local tumor control rates and quality of life and has been widely adopted for the treatment of head and neck cancer in recent decades. Due to the differences in the biological behavior between major and minor SGC, prognoses vary considerably. Herein, we collected and analyzed comprehensive treatment outcomes for major SGC patients treated with surgery and postoperative IMRT, and explored survival, related adverse prognostic factors, treatment failure patterns, and adverse events.

We present the following article in accordance with the Strengthening the Reporting of Observational Studies in Epidemiology (STROBE) checklist (available at https://qims. amegroups.com/article/view/10.21037/qims-21-836/rc).

\section{Methods}

\section{Patients}

We reviewed 75 patients with histologically confirmed primary SGC treated at the First Affiliated Hospital of Zhejiang University from January 2009 to December 2016. Of these, 15 patients were excluded from our retrospective study: 7 had minor SGC, 5 had recurrent or metastatic disease, 2 failed to complete the scheduled RT, and 1 was lost to follow-up. Thus, 60 patients were available for analysis. All patients had newly diagnosed disease and received upfront surgery followed by external beam RT using IMRT. The median follow-up was 55.5 months (Figure 1). Patients with missing data or lost to follow-up were deleted.

The study was conducted in accordance with the Declaration of Helsinki (as revised in 2013). The study was approved by the Institutional Review Board of the First Affiliated Hospital, Zhejiang University, and individual consent for this retrospective analysis was waived.

\section{Evaluation}

All cases were initially evaluated by a multimodality treatment team consisting of an otolaryngologist, a medical oncologist, and an RT oncologist. All cases underwent a detailed physical examination. Histological confirmation of SGC was required before treatment. Axial imaging with computed tomography (CT) was a routine part of patient evaluation, and most cases had also undergone either magnetic resonance imaging (MRI) or positron emission tomography (PET). Histological diagnosis was confirmed according to the World Health Organization (WHO) histologic subtype criteria for SGC (5). All cases were restaged based on the 2018 American Joint Committee on Cancer (AJCC) classification. Acute adverse events were graded according to electronic records. Late toxicity was assessed based on follow-up visits.

\section{Treatment}

All patients underwent initial primary resection, with neck dissection (ND) conducted therapeutically in clinically positive lymph node $(\mathrm{cN}+)$ patients or electively in highrisk clinically negative lymph node (cN0) patients. For 


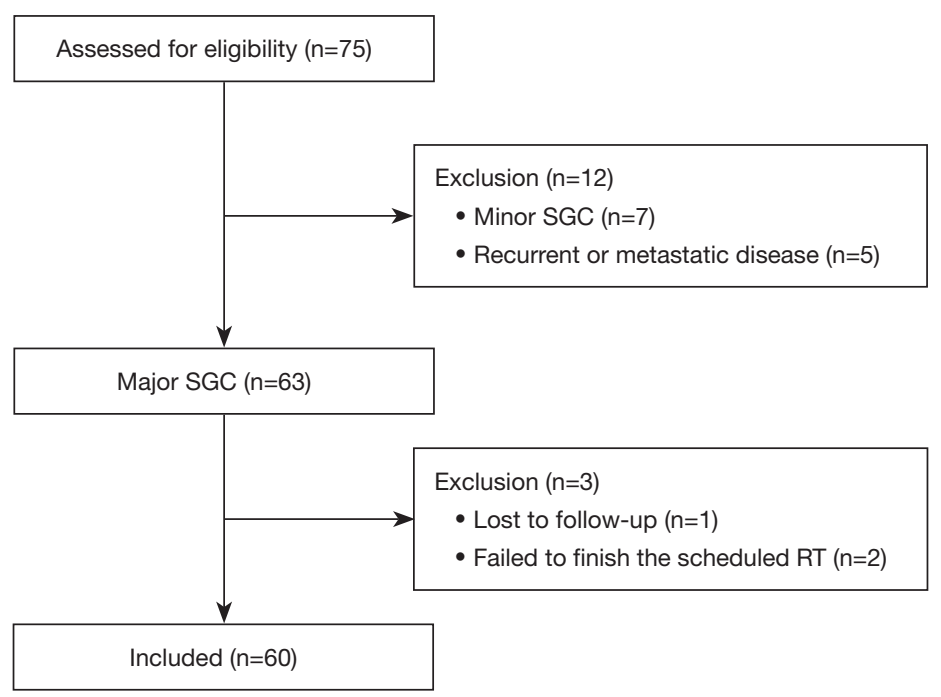

Figure 1 Flowchart of all included patients. SGC, salivary gland cancer; RT, radiotherapy.

IMRT, patients were immobilized in the supine position with a thermoplastic head-neck or head-neck-shoulder mask to ensure the daily reproducibility of treatments. A simulation CT scan was performed with $3 \mathrm{~mm}$ slice thickness and transported to the treatment planning system. The clinical target volume (CTV) was defined as the postoperative tumor bed and the elective nodal area (Figure 2). The elective nodal irradiation target volume comprised the positive lymph nodal areas plus at least 1 level beyond. Organ-at-risk volumes (spinal cord, optic apparatus, and mandible) were delineated on each slice. The maximal dose constraints were below 45 Gy for the spinal cord, 55 Gy for the optic apparatus, and 70 Gy for the mandible. For the planning target volume (PTV), a $0.3 \mathrm{~cm}$ margin was applied to the CTV, considering daily setup error. The prescribed dose was 60-68 Gy, administered at a daily $2 \mathrm{~Gy} /$ fraction, 5 days/week over 6-6.8 weeks (30-34 fractions).

Chemotherapy was administered to patients with advanced disease or in the presence of pathological highrisk factors. Cisplatin $\left(80 \mathrm{mg} / \mathrm{m}^{2}\right.$ intravenously every 3 weeks) was the most commonly used concomitant chemotherapy schedule. Several patients received adjuvant chemotherapy of cisplatin $\left(80 \mathrm{mg} / \mathrm{m}^{2}\right.$ intravenously, day 1) and 5 -fluorouracil (5-FU; $1,000 \mathrm{mg} / \mathrm{m}^{2}$ continuous infusion over $120 \mathrm{~h})$, or cisplatin $\left(80 \mathrm{mg} / \mathrm{m}^{2}\right.$ intravenously, day 1$)$ and capecitabine $\left(1,250 \mathrm{mg} / \mathrm{m}^{2}\right.$ orally twice a day, day 1 to day 14) repeated every 3 weeks, followed by PORT.

\section{Follow-up}

After treatment completion, cases were evaluated every 3 months for the first year, every 3-6 months over the following 4 years, and yearly thereafter. At each follow-up visit, a physical examination and imaging were performed, including fiberoptic endoscopy if indicated. A PET scan was performed if recurrence or metastasis was suspected. Overall survival (OS) was defined as the time from surgery to the date of death, progression-free survival (PFS) as the time from surgery to the date of local or regional recurrence, distant metastases, or death from any cause, locoregional relapse-free survival (LRRFS) as the absence of disease recurrence in the local site or regional lymph node, and distant metastasis-free survival (DMFS) as the time to distant metastasis.

\section{Statistical analysis}

The cumulative incidences of OS, PFS, LRRFS, and DMFS were evaluated using the Kaplan-Meier method. Survival was analyzed using the Kaplan-Meier method, and all subgroups were compared using the log-rank test. Multivariable analysis (MVA) was conducted if there were statistically significant factors in the univariable analysis (UVA). Univariable/multivariable Cox regression analysis was used to assess the association of prognostic factors with survival. The proportional hazards assumption of the Cox model was verified through "logarithm of negative 

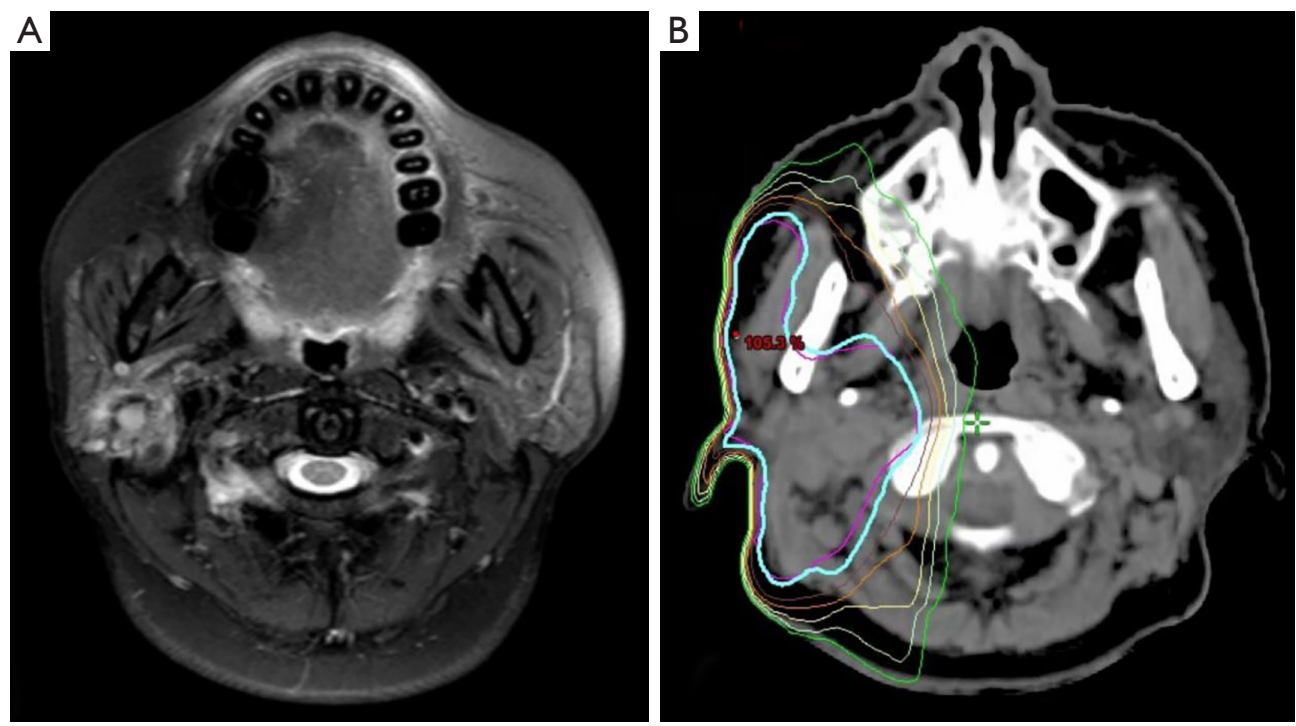

Figure 2 A typical case of right parotid gland tumor (A) axial T2-weighted MRI (B) isodose line of treatment plans of IMRT. MRI, magnetic resonance imaging; IMRT, intensity modulated radiotherapy.

logarithm" to show whether the curves of different groups were parallel and disjointed. A $\mathrm{P}$ value of $<0.05$ was considered significant. Statistical tests were 2-sided. All data were analyzed using the SPSS v. 20.0 (SPSS Inc., Chicago, IL, USA) statistical software package.

\section{Results}

\section{Clinicopatbological characteristics}

Patient characteristics are summarized in Table 1. The median follow-up was 55.5 months (range, 1-114 months). The median age at initial diagnosis was 52 years (range, $15-76$ years). Patients were divided based on age $\leq 52$ or $>52$ years. Among the cases, 35 (58.3\%) were male and 25 $(41.7 \%)$ were female. The median tumor size was $2.5 \mathrm{~cm}$ (range, $1-15 \mathrm{~cm}$ ). Most cases presented with a palpable mass at initial presentation. A total of $23(38.3 \%)$ cases experienced pain and $5(8.3 \%)$ showed facial nerve paralysis. Histologic types included adenoid cystic carcinoma (ACC) in $21(35 \%)$ cases, lymphoepithelial carcinoma (LELC) in $12(20 \%)$ cases, and mucoepidermoid carcinoma (MEC) in $8(13.3 \%)$ cases. The primary sites were the parotid gland in $34(56.7 \%)$ cases, the submandibular gland in 17 (28.3\%) cases, and the sublingual gland in $9(15 \%)$ cases. The tumor stage ( $\mathrm{T}$ stage) distribution included 14 (23.3\%) T1-T2 and $46(76.7 \%)$ T3-T4b patients. The node stage (N stage) distribution was included $41(68.3 \%)$ N0, $8(13.3 \%)$ N1,
$8(13.3 \%) \mathrm{N} 2 \mathrm{~b}$, and $3(5 \%) \mathrm{N} 2 \mathrm{c}$ patients. A total of 11 $(18.3 \%)$ cases presented with stage I-II disease and 49 (81.7\%) cases with stage III-IVb disease. Skin involvement was observed in $5(8.3 \%)$ cases, a positive margin in $7(11.7 \%)$ cases, extra-parenchymal extension in $34(56.7 \%)$ cases, perineural invasion in $19(31.7 \%)$ cases, and major nerve involvement in 28 (46.7\%) cases. Only 16 (26.6\%) cases had pathology results that indicated the grade of cancer, of which 6 were MEC and 4 SDC. Of the 6 MEC patients, 4 had a low/intermediate grade of differentiation.

\section{Treatment characteristics}

All cases received primary tumor resection with curative intention; 42 (70\%) received concurrent ND, of whom $19(31.7 \%)$ had pathologic evidence of $\mathrm{N}+$. The median interval from surgery to RT was 30 days. The interval from surgery to RT (days) was divided based on $\leq 30$ or $>30$ days. The median dose to the tumor bed was 63 Gy (range, 60-68 Gy). A total of 4 patients $(6.7 \%)$ received tumor bed irradiation only and $49(81.7 \%)$ cases received tumor bed and unilateral neck nodal irradiation, while the rest received tumor bed and bilateral neck nodal irradiation. There were 4 patients who received concurrent 3 -weekly cisplatin chemotherapy and 2 patients received adjuvant chemotherapy after PORT, 1 with cisplatin and 5 -FU and the other with cisplatin and capecitabine. Of the 4 patients who received chemotherapy, 2 exhibited advanced 
Table 1 Characteristics of the 60 SGC patients

\begin{tabular}{|c|c|}
\hline Characteristics & $\mathrm{n}(\%)$ \\
\hline Median age (years) & 52 \\
\hline \multicolumn{2}{|l|}{ Gender } \\
\hline Male & $35(58.3)$ \\
\hline Female & $25(41.7)$ \\
\hline \multicolumn{2}{|l|}{ Primary site } \\
\hline Parotid gland & $34(56.7)$ \\
\hline Submandibular gland & $17(28.3)$ \\
\hline Sublingual gland & $9(15.0)$ \\
\hline Median size of tumor $(\mathrm{cm})$ & 2.5 \\
\hline \multicolumn{2}{|l|}{ Pain } \\
\hline Yes & $23(38.3)$ \\
\hline No & $37(61.7)$ \\
\hline \multicolumn{2}{|l|}{ Facial nerve paralysis } \\
\hline Yes & $5(8.3)$ \\
\hline No & $55(91.7)$ \\
\hline \multicolumn{2}{|l|}{ Histologic types } \\
\hline ACC & $21(35.0)$ \\
\hline LELC & $12(20.0)$ \\
\hline MEC & $8(13.3)$ \\
\hline SDC & $5(8.3)$ \\
\hline SCC & $4(6.7)$ \\
\hline BCAC & $3(5.0)$ \\
\hline Myoepithelial carcinoma & $2(3.3)$ \\
\hline $\mathrm{AcCC}$ & $1(1.7)$ \\
\hline Others & $4(6.7)$ \\
\hline \multicolumn{2}{|l|}{ Clinical stage } \\
\hline I-II & $11(18.3)$ \\
\hline $\mathrm{III-IVb}$ & $49(81.7)$ \\
\hline \multicolumn{2}{|l|}{ Skin involvement } \\
\hline Yes & $5(8.3)$ \\
\hline No & $55(91.7)$ \\
\hline \multicolumn{2}{|l|}{ Margin } \\
\hline Positive & $7(11.7)$ \\
\hline Negative & $53(88.3)$ \\
\hline
\end{tabular}

Table 1 (continued)
Table 1 (continued)

\begin{tabular}{|c|c|}
\hline Characteristics & n (\%) \\
\hline \multicolumn{2}{|l|}{ Extra-parenchymal extension } \\
\hline Yes & $34(56.7)$ \\
\hline No & $26(43.3)$ \\
\hline \multicolumn{2}{|l|}{ Perineural invasion } \\
\hline Yes & 19 (31.7) \\
\hline No & $41(68.3)$ \\
\hline \multicolumn{2}{|l|}{ Major nerve involvement } \\
\hline Positive & $28(46.7)$ \\
\hline Negative & $32(53.3)$ \\
\hline \multicolumn{2}{|l|}{ Surgery } \\
\hline Primary tumor resection & $18(30.0)$ \\
\hline Primary tumor resection + ND & $42(70.0)$ \\
\hline \multicolumn{2}{|l|}{ Interval from surgery to RT (days) } \\
\hline$\leq 30$ & $30(50.0)$ \\
\hline$>30$ & $30(50.0)$ \\
\hline \multicolumn{2}{|l|}{ RT } \\
\hline \multicolumn{2}{|l|}{ T stage } \\
\hline T1-T2 & $14(23.3)$ \\
\hline T3-T4b & $46(76.7)$ \\
\hline \multicolumn{2}{|l|}{$\mathrm{N}$ stage } \\
\hline NO & $41(68.3)$ \\
\hline N1 & $8(13.3)$ \\
\hline $\mathrm{N} 2 \mathrm{~b}$ & 8 (13.3) \\
\hline $\mathrm{N} 2 \mathrm{c}$ & $3(5.0)$ \\
\hline Tumor bed & $4(6.7)$ \\
\hline Tumor bed + unilateral neck & $49(81.7)$ \\
\hline Tumor bed + bilateral neck & $7(11.6)$ \\
\hline Median dose (Gy) & 63 \\
\hline \multicolumn{2}{|l|}{ Chemoradiotherapy } \\
\hline Yes & $4(6.7)$ \\
\hline No & $56(93.3)$ \\
\hline
\end{tabular}

SGC, salivary gland cancer; ACC, adenoid cystic carcinoma; LELC, Iymphoepithelioid carcinoma; MEC, mucoepidermoid carcinoma; SDC, salivary duct carcinoma; SCC, squamous cell carcinoma; BCAC, basal cell adenocarcinoma; AcCC, acinic cell carcinoma; ND, neck dissection; RT, radiotherapy. 
A

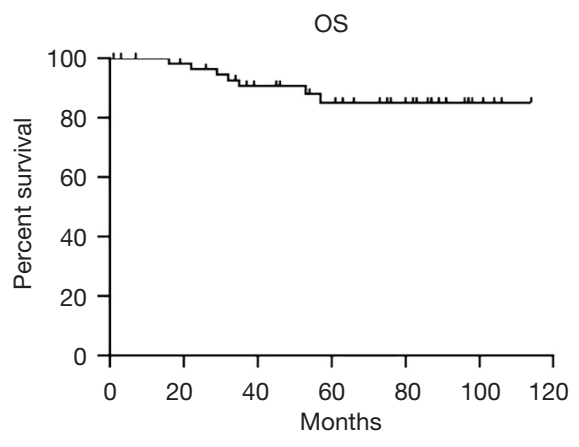

Patients at risk $\quad \begin{array}{llllll}60 & 55 & 40 & 30 & 21 & 5\end{array}$

C

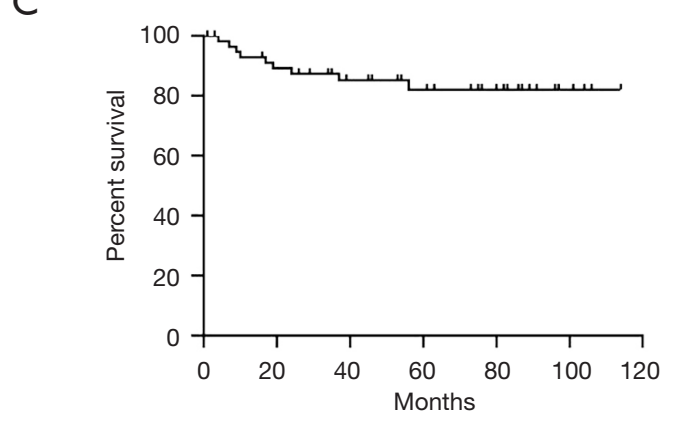

B

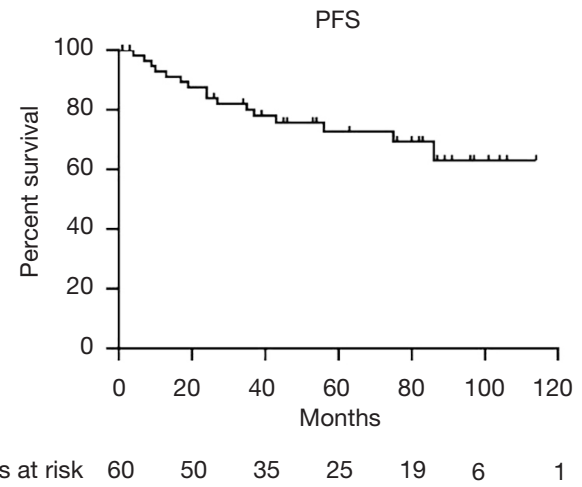

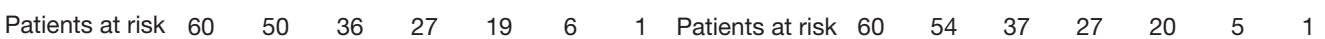

Figure 3 Kaplan-Meier curves of OS, PFS, LRRFS, and DMFS. OS, overall survival; PFS, progression-free survival; LRRFS, locoregional relapse-free survival; DMFS, distant metastasis-free survival.

nodal stage (N2b) disease and 2 exhibited major nerve involvement; all presented with stage T3-T4 disease.

\section{Survival analysis}

Kaplan-Meier curves for OS, PFS, LRRFS, and DMFS are shown in Figure 3. The 3-, 5-, and 10-year OS rates were $90.7 \%, 85.1 \%$, and $85.1 \%$, while the PFS rates were $80.1 \%$, $72.7 \%$, and $63.1 \%$, respectively. The 3-, 5-, and 10 -year LRRFS rates were $87.4 \%, 82.1 \%$, and $82.1 \%$, respectively, while the DMFS rates were $85.3 \%, 78.4 \%$, and $66.1 \%$, respectively.

\section{Prognostic factors for $O S$}

Risk factors for survival are summarized in Table 2 and Table S1. The UVA suggested that a higher $\mathrm{N}$ stage was associated with decreased survival, with stage N0 disease patients surviving significantly longer than those with stages $\mathrm{N} 1, \mathrm{~N} 2 \mathrm{~b}$, and $\mathrm{N} 2 \mathrm{c}(\mathrm{P}=0.025)$. The primary site was a prognostic factor for OS, with 5 -year OS rates of $90 \%, 67.6 \%$, and $100 \%$ for parotid, submandibular, and sublingual gland tumors $(\mathrm{P}=0.039)$, respectively. However, no significant association was found between OS and $\mathrm{N}$ stage or the primary site in MVA.

\section{Prognostic factors for PFS}

Based on our log-rank test, gender was strongly associated with PFS $(\mathrm{P}=0.018)$, although it did not reach significance as a predictor in MVA. For patients with and without major nerve involvement, the 5 -year PFS was $85 \%$ and $59.5 \%(\mathrm{P}=0.019)$, respectively. Notably, when interval from surgery to RT was analyzed as a categorical variable using the median interval of 30 days as a cutpoint, a significant difference in PFS was observed $(\mathrm{P}=0.044)$. No significant difference in PFS was observed among patients with $\mathrm{N}$ stage and positive margin in UVA $(\mathrm{P}=0.164$ and 0.092 , respectively). The MVA indicated that major nerve involvement hazard ratio $(\mathrm{HR})=2.394 ; 95 \%$ confidence 
Table 2 UVA and MVA for OS and PFS

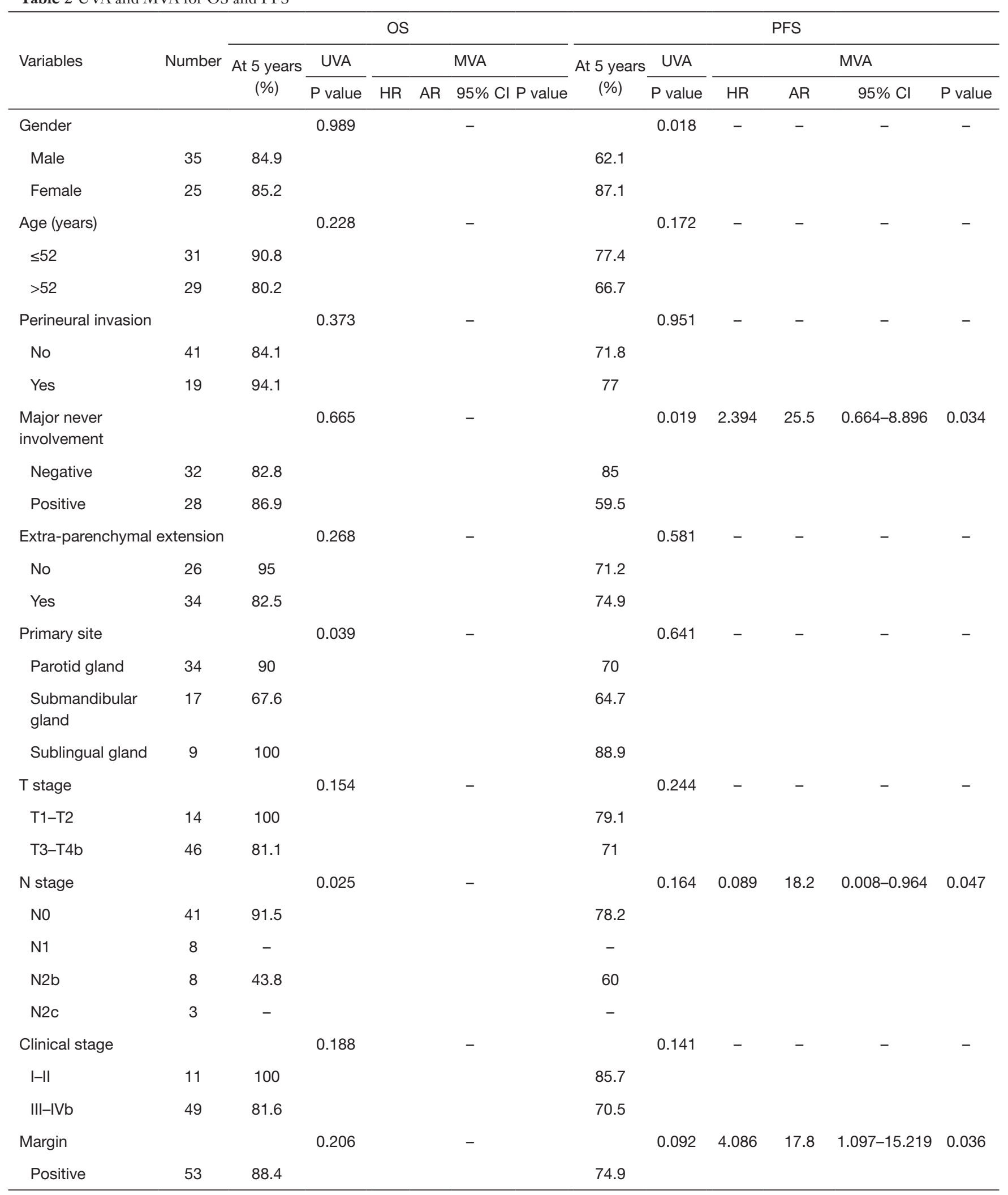

Table 2 (continued) 
Table 2 (continued)

\begin{tabular}{|c|c|c|c|c|c|c|c|c|c|c|c|c|}
\hline \multirow{3}{*}{ Variables } & \multirow{3}{*}{ Number } & \multicolumn{5}{|c|}{ OS } & \multicolumn{6}{|c|}{ PFS } \\
\hline & & \multirow{2}{*}{$\begin{array}{c}\text { At } 5 \text { years } \\
(\%)\end{array}$} & \multirow{2}{*}{$\frac{\text { UVA }}{P \text { value }}$} & \multicolumn{3}{|r|}{ MVA } & \multirow{2}{*}{$\begin{array}{l}\text { At } 5 \text { years } \\
(\%)\end{array}$} & \multirow{2}{*}{$\frac{\text { UVA }}{P \text { value }}$} & \multicolumn{4}{|c|}{ MVA } \\
\hline & & & & $\mathrm{HR}$ & $A R$ & $95 \% \mathrm{Cl} P$ value & & & $\mathrm{HR}$ & $A R$ & $95 \% \mathrm{Cl}$ & $P$ value \\
\hline Negative & 7 & 64.3 & & & & & 57.1 & & & & & \\
\hline Skin involvement & & & 0.55 & & & - & & 0.458 & - & - & - & - \\
\hline Yes & 5 & 80 & & & & & 40 & & & & & \\
\hline $\begin{array}{l}\text { Interval from surge } \\
\text { (days) }\end{array}$ & y to $R T$ & & 0.635 & & & - & & 0.044 & 3.934 & 25.6 & $1.097-14.105$ & 0.036 \\
\hline$\leq 30$ & 30 & 84.7 & & & & & 85.2 & & & & & \\
\hline
\end{tabular}

P was calculated using log-rank test. UVA, univariable analysis; MVA, multivariable analysis; OS, overall survival; PFS, progression-free survival; HR, hazard ratio; $\mathrm{AR}$, absolute risk; $\mathrm{Cl}$, confidence interval; $\mathrm{RT}$, radiotherapy.

interval (CI): 0.664-8.896; $\mathrm{P}=0.034], \mathrm{N}$ stage $(\mathrm{HR}=0.089$; 95\% CI: $0.008-0.964 ; \mathrm{P}=0.047)$, positive margin (HR $=4.086 ; 95 \% \mathrm{CI}: 1.097-15.219 ; \mathrm{P}=0.036)$, and interval from surgery to RT (HR =3.934; 95\% CI: 1.097-14.105; $\mathrm{P}=0.036)$ were significant independent predictors of PFS (Figure 4).

\section{Prognostic factors for LRRFS}

In UVA, the 5-year LRRFS rate for patients with a positive margin was $57.1 \%$, compared with $85.9 \%$ for those with a negative margin $(\mathrm{P}=0.029)$. In MVA, the positive margin was an independent predictor for LRRFS (HR $=5.064 ; 95 \%$ CI: 1.211-21.187; $\mathrm{P}=0.026$ ) (Figure 5).

\section{Prognostic factors for DMFS}

Major nerve involvement $(\mathrm{P}=0.024), \mathrm{N}$ stage $(\mathrm{P}=0.014)$, and clinical stage $(\mathrm{P}=0.049)$ were prognostic factors for poor DMFS in UVA. When a Cox proportional hazards regression model was used to predict distant metastases, major nerve involvement ( $\mathrm{HR}=2.115$; 95\% CI: 0.521-8.583; $\mathrm{P}=0.008)$, positive margin $(\mathrm{HR}=6.367 ; 95 \% \mathrm{CI}: 1.524$ 26.603; $\mathrm{P}=0.011$ ), and interval from surgery to RT (HR $=6.231 ; 95 \%$ CI: $1.503-25.829 ; \mathrm{P}=0.012$ ) were identified as independent predictors of distant metastases (Figure 5).

In ACC subgroup analysis, 5-year OS, PFS, LRRFS, and DMFS rates were $100 \%, 85.7 \%, 76.2 \%$, and $90.2 \%$, respectively. In UVA, perineural invasion was significantly associated with PFS $(\mathrm{P}=0.021)$ and DMFS $(\mathrm{P}=0.026)$, major nerve involvement was strongly associated with PFS $(\mathrm{P}=0.014)$, the parotid gland $(\mathrm{P}=0.041)$, and $\mathrm{N}$ stage $(\mathrm{P}=0.023)$ were associated with poor LRRFS; and positive margin was an important prognostic factor for PFS ( $\mathrm{P}=0.021)$, LRRFS $(\mathrm{P}=0.002)$, and DMFS $(\mathrm{P}=0.021)$. However, there were too few ACCs to allow for MVA. For detailed information, see Table 3.

\section{Adverse events}

The most acute adverse events were grade II/III mucositis $(n=44 ; 73.3 \%)$ and grade I/II dermatitis $(n=46 ; 76.7 \%)$. Xerostomia was the most common late adverse event $(n=18$; $30 \%)$, followed by hearing impairment ( $\mathrm{n}=17 ; 28.4 \%)$, taste abnormalities $(n=15 ; 25 \%)$, paresthesia $(n=14 ; 23.3 \%)$, fibrosis of the skin $(n=11 ; 18.3 \%)$, trismus $(n=6 ; 10 \%)$, and osteoradionecrosis $(n=2 ; 3.3 \%)$. No grade 4 acute or late adverse events were observed.

\section{Patterns of failure}

Treatment failure occurred in $16(26.7 \%)$ of the 60 cases (Figure 6). Locoregional recurrence occurred in 9 (15\%), local failure in $8(13.3 \%)$, and regional failure in $3(5 \%)$ cases. Distant metastasis occurred in 14 cases $(23.3 \%)$. In the 7 cases with distance-related failure, metastasis was accompanied by locoregional recurrence. The median time to distant metastasis was 49.5 months. Distant metastasis 
A

PFS

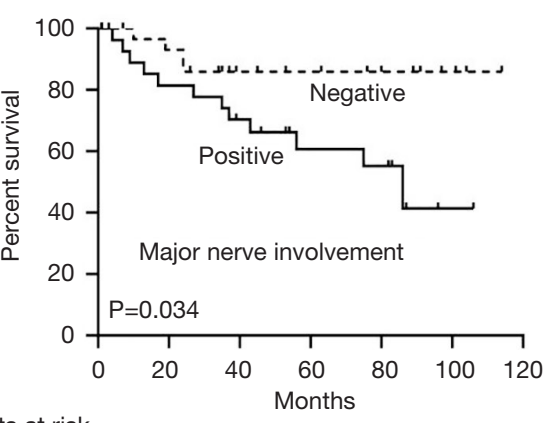

Patients at risk

$\begin{array}{llllllll}\text { Positive } & 28 & 21 & 17 & 13 & 12 & 2 & 1 \\ \text { Negative } & 32 & 29 & 18 & 13 & 9 & 4 & 1\end{array}$

C

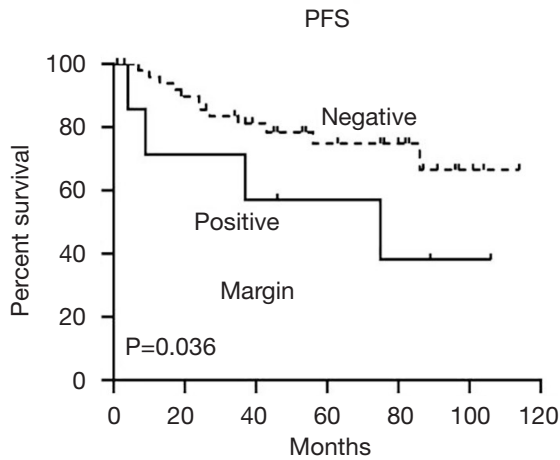

Patients at risk

$\begin{array}{llllllll}\text { Positive } & 7 & 6 & 5 & 4 & 3 & 2 & 1 \\ \text { Negative } & 53 & 45 & 31 & 22 & 17 & 5 & 1\end{array}$
B

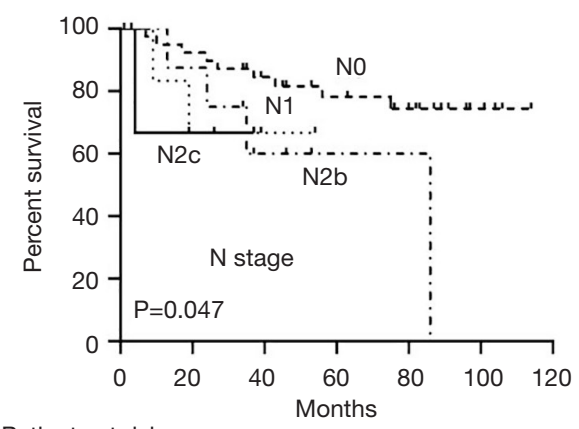

Patients at risk

$\begin{array}{llllllll}\text { No } & 41 & 37 & 30 & 24 & 18 & 6 & 1 \\ \text { N1 } & 8 & 5 & 2 & 1 & 1 & 1 & 1 \\ \text { N2b } & 8 & 8 & 4 & 2 & 2 & 1 & 1 \\ \text { N2C } & 3 & 2 & 1 & 1 & 1 & 1 & 1\end{array}$

D

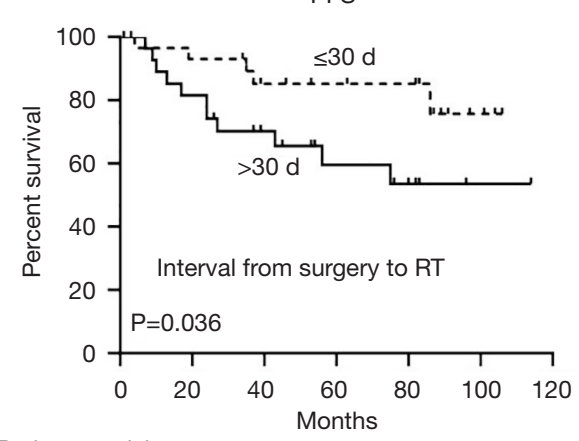

Patients at risk

$\begin{array}{llllllll}\leq 30 & 30 & 28 & 19 & 16 & 14 & 5 & 1 \\ >30 & 30 & 23 & 16 & 11 & 7 & 2 & 1\end{array}$

Figure 4 Comparison of survival according to clinicopathologic factors. (A) Major nerve involvement $(\mathrm{P}=0.034)$; (B) N stage (P=0.047); (C) margin ( $\mathrm{P}=0.036)$; (D) interval from surgery to $\mathrm{RT}(\mathrm{P}=0.036)$. PFS, progression-free survival; RT, radiotherapy.

occurred in the lung $(\mathrm{n}=10 ; 16.7 \%)$, bones $(\mathrm{n}=3 ; 5 \%)$, brain $(\mathrm{n}=1 ; 1.7 \%)$, elsewhere $(\mathrm{n}=1 ; 1.7 \%)$, and at multiple sites $(\mathrm{n}=2 ; 3.3 \%)$.

\section{Discussion}

This retrospective study focused on the clinical outcomes, prognostic factors, failure patterns, and adverse events in patients with major SGC treated with surgery and postoperative IMRT. Similar to already reported in the literature $(3,6,7)$, our study showed that ACC was the most common histology, followed by LELC. As histology is an important prognostic factor in SDC patients and adenocarcinoma and undifferentiated carcinoma have worse prognoses $(8,9)$, we performed an ACC subgroup analysis. Our cohort exhibited excellent clinical outcomes that compared very favorably with those reported in the literature (10).

Our MVA showed that $\mathrm{N}$ stage, positive margin, major nerve involvement, and interval from surgery to RT were unfavorable prognostic factors. With regard to the relationship between clinicopathologic parameters and OS, there was no negative prognostic factor for survival in MVA. A probable reason was the excellent survival of our patients. Although positive margin and $\mathrm{N}$ stage were not prognostic factors for PFS in the UVA, and neither was $\mathrm{N}$ stage for LRRFS, we nevertheless included them in the Cox proportional hazards regression model, as positive margin and positive lymph nodes had previously been shown to be important predictive factors for SGC (3,11-13). After adjusting for factors that might affect prognosis, $\mathrm{N}$ stage and positive margin were found to be independent prognostic 
A

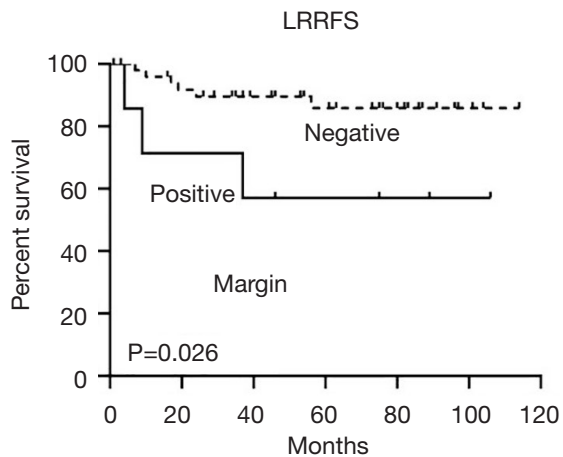

Patients at risk

$\begin{array}{llllllll}\text { Positive } & 7 & 6 & 5 & 4 & 3 & 2 & 1 \\ \text { Negative } & 53 & 45 & 32 & 24 & 17 & 5 & 1\end{array}$

C

DMFS

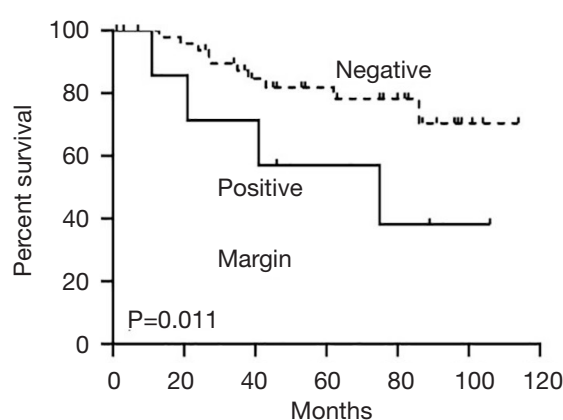

Patients at risk

$\begin{array}{llllllll}\text { Positive } & 7 & 7 & 6 & 4 & 3 & 2 & 1 \\ \text { Negative } & 53 & 48 & 32 & 24 & 18 & 4 & 1\end{array}$

B

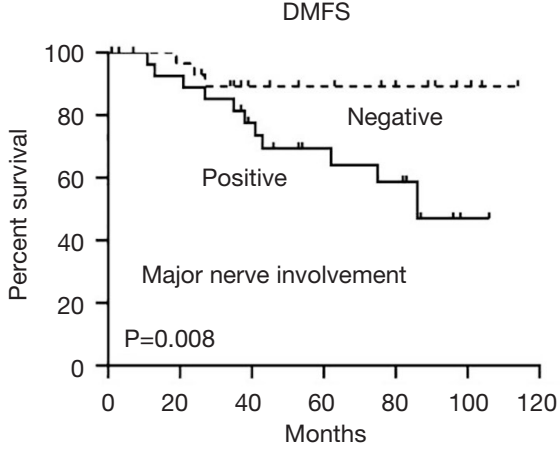

Patients at risk

$\begin{array}{llllllll}\text { Positive } & 28 & 25 & 19 & 14 & 12 & 2 & 1\end{array}$

$\begin{array}{llllllll}\text { Negative } & 32 & 29 & 17 & 15 & 10 & 5 & 1\end{array}$

D

DMFS

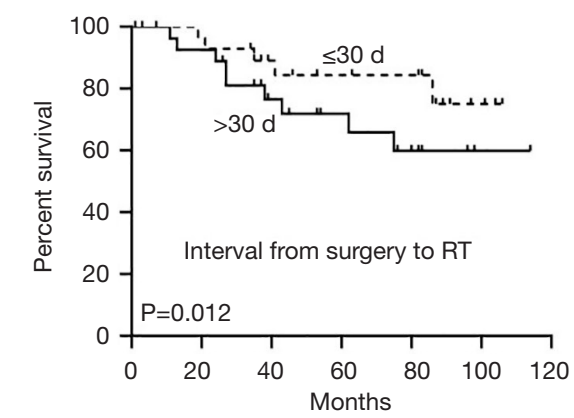

Patients at risk

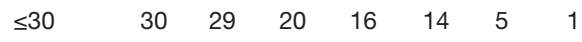

$\begin{array}{llllllll}>30 & 30 & 26 & 17 & 13 & 8 & 2 & 1\end{array}$

Figure 5 Comparison of survival according to clinicopathologic factors. (A) Margin $(\mathrm{P}=0.026)$; (B) major nerve involvement $(\mathrm{P}=0.008)$; $(\mathrm{C})$ margin ( $\mathrm{P}=0.011)$; (D) interval from surgery to RT ( $\mathrm{P}=0.012)$. LRRFS, locoregional relapse-free survival; DMFS, distant metastasis-free survival; RT, radiotherapy.

factors for PFS, although $\mathrm{N}$ stage was not a predictive factor for LRRFS. Positive margin was also an independent prognostic factor for LRRFS and DMFS, suggesting that margin status information should be included in clinical pathology reports. Major nerve involvement was an independent prognostic factor for poor PFS and DMFS, while a time from surgery to RT $>30$ days resulted in worse PFS and DMFS. A previous study showed clear tendencies for worsening effects of poor differentiation in SCC and high grade in MEC (14). Other research has shown that high-grade tumor histology is a highly significant predictor of shorter survival in SGC, irrespective of histological subtype (15). The subgroups of patients with MEC and SCC were too small to allow adequate statistical analysis.

Combination treatment modalities are usually required for SGC. Surgical resection followed by PORT is practical and effective at increasing survival and locoregional control rates in patients with a tumor size $\geq 4 \mathrm{~cm}$, deep lobe settlement, high grade tumor, positive margin, local advanced stage, lymph node metastasis, soft tissue or bone infiltration, and perivascular and perineural invasion (16-19). Terhaard et al. (20) revealed that the 5- and 10-year actuarial local control rates were significantly higher for PORT vs. surgery alone (94\% vs. $84 \%$ and $91 \%$ vs. $76 \%$, respectively; $\mathrm{P}=0.0005)$. Scherl et al. (21) showed that postoperative chemoradiotherapy (POCRT) in high-risk and high-grade SDC patients featured with perineural invasion, positive margins, advanced $\mathrm{T}$ status, or lymph node involvement which reduced the rate of locoregional recurrences.

A comparison of our outcomes with those of other 
Table 3 UVA of prognostic factors for ACC

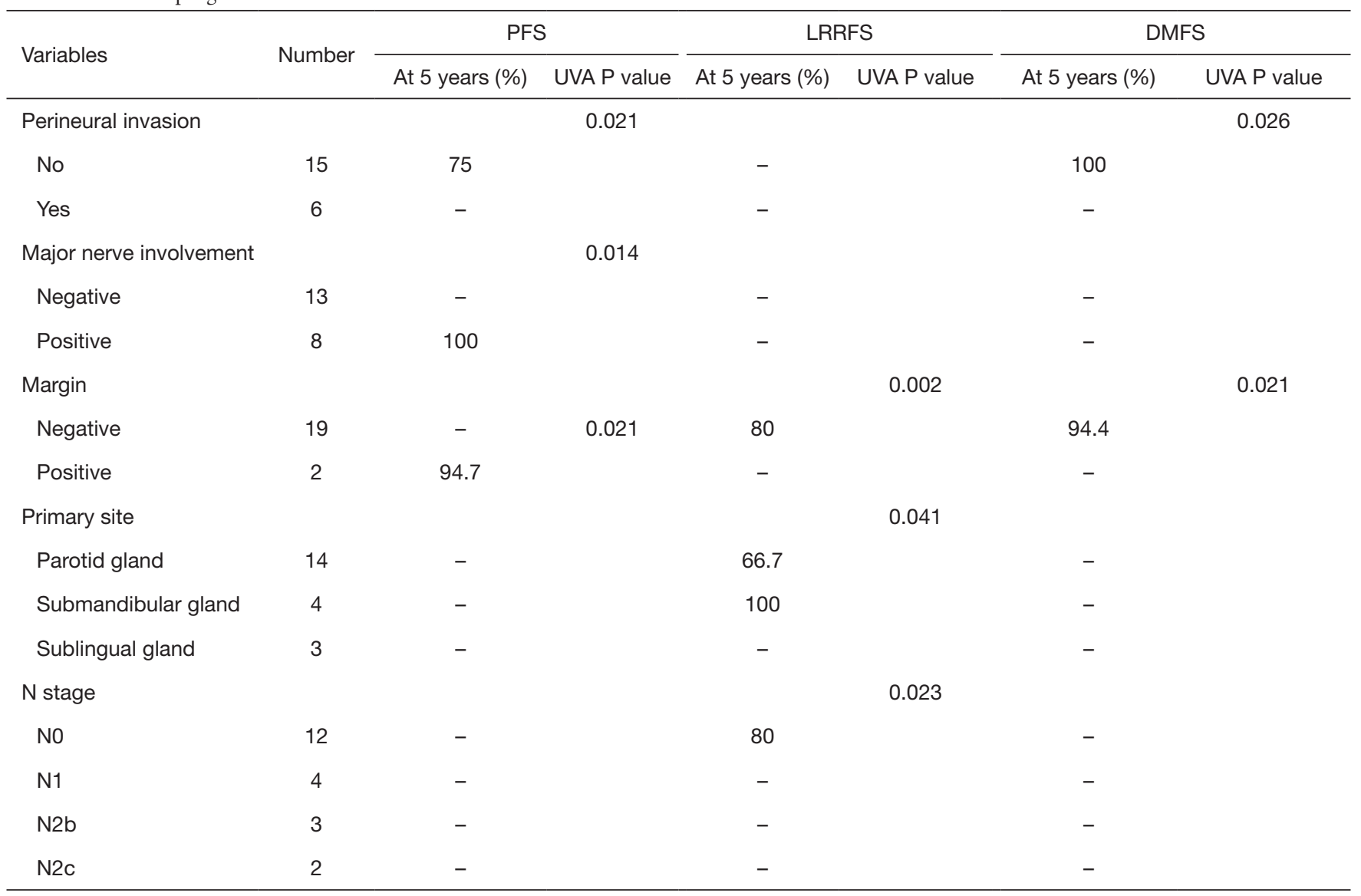

P was calculated using log-rank test. UVA, univariable analysis; ACC, adenoid cystic carcinoma; PFS, progression-free survival; LRRFS, locoregional relapse-free survival; DMFS, distant metastasis-free survival.

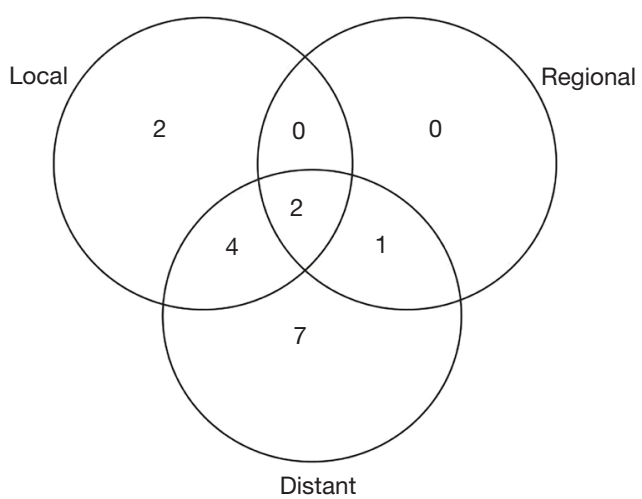

Figure 6 Venn diagram of patterns of failure (16/60 patients).

institutions would be difficult due to the different case mix and wide variety of histological subtypes involved. Overall, the outcomes in our study are better than the reported historical data of other institutions using PORT for SGC treatment (5-year OS: $85.1 \%$ vs. $61-74 \%$; 10-year OS: $85.1 \%$ vs. $48-71 \%)(17,18,22-24)$. The better survival rates in this series could be explained by a "cohort effect" resulting from improved diagnostic capabilities and treatment modalities. Previous studies have involved conventional RT or 3-DCRT treatment; however, all the cases in this study received IMRT. Compared with conventional RT or 3-DCRT, IMRT permits a greater precision and modulation of the RT beam to keep high doses away from vital structures. It offers improved locoregional control in SGC patients, which corresponds to better OS $(25,26)$. Furthermore, because a more generous amount of normal tissue is spared, IMRT is less toxic, resulting in a smaller impact on quality of life (27). Our patients exhibited a reduced incidence of xerostomia (30\%) compared with those from historical studies $(83 \%)(28,29)$.

In agreement with the published literature $(30,31)$, 
distant metastasis was the predominant mode of failure, highlighting the need for effective systemic therapies. Chemotherapy is generally reserved for the palliative treatment of symptomatic locally recurrent or metastatic disease, and has a limited effect (32). Recent studies have also indicated that POCRT promotes higher survival and locoregional control than PORT treatment alone (33-36). However, no significant differences in DMFS, disease-free survival, and OS were observed when adding concurrent chemotherapy to PORT, while POCRT has been associated with increased mortality and toxicity $(35,37)$. We could not evaluate the effect of POCRT on outcomes owing to the small number of patients who received chemotherapy.

Our study had several significant limitations. The small sample size did not permit an evaluation of outcomes stratified by various histological subtypes. Additionally, our median follow-up was approximately 55.5 months, and median OS, PFS, LRRFS, and DMFS were not reached. Lastly, the pathological detection of SGC margin status and perineural invasion may vary greatly depending on the sampling extent. Nevertheless, our observations have the potential for use in the design of prospective SGC clinical trials.

\section{Conclusions}

Our series of 60 SGC patients showed that postoperative IMRT led to the improved OS for SGC with acceptable toxicities. The $\mathrm{N}$ stage, positive margin, major nerve involvement, and interval from surgery to RT were important factors associated with oncological outcomes.

\section{Acknowledgments}

Funding: This study was an independent research funded by the Department of Health of Zhejiang Province (No. 2018265493 and No. 2017197137).

\section{Footnote}

Reporting Checklist: The authors have completed the STROBE reporting checklist. Available at https://qims. amegroups.com/article/view/10.21037/qims-21-836/rc

Conflicts of Interest: All authors have completed the ICMJE uniform disclosure form (available at https://qims. amegroups.com/article/view/10.21037/qims-21-836/ coif). All authors report that this study was an independent research funded by the Department of Health of Zhejiang Province (grant No. 2018265493 and No. 2017197137). The authors have no other conflicts of interest to declare.

Ethical Statement: The authors are accountable for all aspects of the work in ensuring that questions related to the accuracy or integrity of any part of the work are appropriately investigated and resolved. The study was conducted in accordance with the Declaration of Helsinki (as revised in 2013). The study was approved by Institutional Review Board of the First Affiliated Hospital, Zhejiang University, and individual consent for this retrospective analysis was waived.

Open Access Statement: This is an Open Access article distributed in accordance with the Creative Commons Attribution-NonCommercial-NoDerivs 4.0 International License (CC BY-NC-ND 4.0), which permits the noncommercial replication and distribution of the article with the strict proviso that no changes or edits are made and the original work is properly cited (including links to both the formal publication through the relevant DOI and the license). See: https://creativecommons.org/licenses/by-nc-nd/4.0/.

\section{References}

1. Ata-Ali J, Zurriaga O, Alberich C. Incidence and survival rates for malignant salivary gland tumors. J Oral Sci 2016;58:67-73.

2. Spiro RH. Salivary neoplasms: overview of a 35year experience with 2,807 patients. Head Neck Surg 1986;8:177-84.

3. Terhaard CH, Lubsen H, Van der Tweel I, Hilgers FJ, Eijkenboom WM, Marres HA, Tjho-Heslinga RE, de Jong JM, Roodenburg JL; Dutch Head and Neck Oncology Cooperative Group. Salivary gland carcinoma: independent prognostic factors for locoregional control, distant metastases, and overall survival: results of the Dutch head and neck oncology cooperative group. Head Neck 2004;26:681-92; discussion 692-3.

4. Lima RA, Tavares MR, Dias FL, Kligerman J, Nascimento MF, Barbosa MM, Cernea CR, Soares JR, Santos IC, Salviano S. Clinical prognostic factors in malignant parotid gland tumors. Otolaryngol Head Neck Surg 2005;133:702-8.

5. Thompson L. World Health Organization classification of tumours: pathology and genetics of head and neck tumours. Ear Nose Throat J 2006;85:74. 
6. Bell RB, Dierks EJ, Homer L, Potter BE. Management and outcome of patients with malignant salivary gland tumors. J Oral Maxillofac Surg 2005;63:917-28.

7. Kaur J, Goyal S, Muzumder S, Bhasker S, Mohanti BK, Rath GK. Outcome of surgery and post-operative radiotherapy for major salivary gland carcinoma: ten year experience from a single institute. Asian Pac J Cancer Prev 2014;15:8259-63.

8. Wahlberg P, Anderson H, Biörklund A, Möller T, Perfekt R. Carcinoma of the parotid and submandibular glands - a study of survival in 2465 patients. Oral Oncol 2002;38:706-13.

9. Jang JY, Choi N, Ko YH, Chung MK, Son YI, Baek CH, Baek KH, Jeong HS. Treatment outcomes in metastatic and localized high-grade salivary gland cancer: high chance of cure with surgery and post-operative radiation in T1-2 N0 high-grade salivary gland cancer. BMC Cancer 2018;18:672.

10. Ali S, Palmer FL, Katabi N, Lee N, Shah JP, Patel SG, Ganly I. Long-term local control rates of patients with adenoid cystic carcinoma of the head and neck managed by surgery and postoperative radiation. Laryngoscope 2017;127:2265-9.

11. Qian K, Di L, Guo K, Zheng X, Ji Q, Wang Z. Cervical Lymph Node Metastatic Status and Adjuvant Therapy Predict the Prognosis of Salivary Duct Carcinoma. J Oral Maxillofac Surg 2018;76:1578-86.

12. Yoo SH, Roh JL, Kim SO, Cho KJ, Choi SH, Nam SY, Kim SY. Patterns and treatment of neck metastases in patients with salivary gland cancers. J Surg Oncol 2015;111:1000-6.

13. Johnston ML, Huang SH, Waldron JN, Atenafu EG, Chan K, Cummings BJ, Gilbert RW, Goldstein D, Gullane PJ, Irish JC, Perez-Ordonez B, Weinreb I, Bayley A, Cho J, Dawson LA, Hope A, Ringash J, Witterick IJ, O'Sullivan B, Kim J. Salivary duct carcinoma: Treatment, outcomes, and patterns of failure. Head Neck 2016;38 Suppl 1:E820-6.

14. Zamani M, Grønhøj C, Schmidt Jensen J, von Buchwald C, Charabi BW, Hjuler T. Survival and characteristics of pediatric salivary gland cancer: A systematic review and meta-analysis. Pediatr Blood Cancer 2019;66:e27543.

15. Westergaard-Nielsen M, Godballe C, Eriksen JG, Larsen SR, Kiss K, Agander T, Ulhøi BP, Charabi B, Klug TE, Jacobsen H, Johansen J, Kristensen CA, Andersen E, Andersen M, Andreasen S, Bjørndal K. Salivary gland carcinoma in Denmark: a national update and followup on incidence, histology, and outcome. Eur Arch Otorhinolaryngol 2021;278:1179-88.
16. Cerda T, Sun XS, Vignot S, Marcy PY, Baujat B, Baglin AC, Ali AM, Testelin S, Reyt E, Janot F, Thariat J. A rationale for chemoradiation (vs radiotherapy) in salivary gland cancers? On behalf of the REFCOR (French rare head and neck cancer network). Crit Rev Oncol Hematol 2014;91:142-58.

17. Storey MR, Garden AS, Morrison WH, Eicher SA, Schechter NR, Ang KK. Postoperative radiotherapy for malignant tumors of the submandibular gland. Int J Radiat Oncol Biol Phys 2001;51:952-8.

18. North CA, Lee DJ, Piantadosi S, Zahurak M, Johns ME. Carcinoma of the major salivary glands treated by surgery or surgery plus postoperative radiotherapy. Int J Radiat Oncol Biol Phys 1990;18:1319-26.

19. Pohar S, Gay H, Rosenbaum P, Klish D, Bogart J, Sagerman R, Hsu J, Kellman R. Malignant parotid tumors: presentation, clinical/pathologic prognostic factors, and treatment outcomes. Int J Radiat Oncol Biol Phys 2005;61:112-8.

20. Terhaard CH, Lubsen H, Rasch CR, Levendag PC, Kaanders HH, Tjho-Heslinga RE, van Den Ende PL, Burlage F; Dutch Head and Neck Oncology Cooperative Group. The role of radiotherapy in the treatment of malignant salivary gland tumors. Int J Radiat Oncol Biol Phys 2005;61:103-11.

21. Scherl C, Haderlein M, Agaimy A, Mantsopoulos K, Koch M, Traxdorf M, Fietkau R, Grundtner P, Iro H. Outcome and management of rare high-grade "salivary" adenocarcinoma: the important role of adjuvant (chemo) radiotherapy. Strahlenther Onkol 2019;195:1050-9.

22. Toonkel LM, Guha S, Foster P, Dembrow V. Radiotherapy for parotid cancer. Ann Surg Oncol 1994;1:468-72.

23. Fitzpatrick PJ, Theriault C. Malignant salivary gland tumors. Int J Radiat Oncol Biol Phys 1986;12:1743-7.

24. Bhide SA, Miah A, Barbachano Y, Harrington KJ, Newbold K, Nutting CM. Radical radiotherapy for treatment of malignant parotid tumours: a single centre experience 1995-2005. Br J Oral Maxillofac Surg 2009;47:284-9.

25. Chen JL, Huang YS, Kuo SH, Hong RL, Ko JY, Lou PJ, Wang CW. Intensity-modulated radiation therapy achieves better local control compared to three-dimensional conformal radiation therapy for T4-stage nasopharyngeal carcinoma. Oncotarget 2017;8:14068-77.

26. Hosni A, Huang SH, Goldstein D, Xu W, Chan B, Hansen A, Weinreb I, Bratman SV, Cho J, Giuliani M, Hope A, Kim J, O’Sullivan B, Waldron J, Ringash J. Outcomes and prognostic factors for major salivary gland 
carcinoma following postoperative radiotherapy. Oral Oncol 2016;54:75-80.

27. van der Veen J, Nuyts S. Can Intensity-ModulatedRadiotherapy Reduce Toxicity in Head and Neck Squamous Cell Carcinoma? Cancers (Basel) 2017;9:135.

28. Nutting CM, Morden JP, Harrington KJ, Urbano TG, Bhide SA, Clark C, Miles EA, Miah AB, Newbold K, Tanay M, Adab F, Jefferies SJ, Scrase C, Yap BK, A'Hern RP, Sydenham MA, Emson M, Hall E; PARSPORT trial management group. Parotid-sparing intensity modulated versus conventional radiotherapy in head and neck cancer (PARSPORT): a phase 3 multicentre andomized controlled trial. Lancet Oncol 2011;12:127-36.

29. Bruvo M, Mahmood F. Apparent diffusion coefficient measurement of the parotid gland parenchyma. Quant Imaging Med Surg 2021;11:3812-29.

30. Samant S, van den Brekel MW, Kies MS, Wan J, Robbins KT, Rosenthal DI, Rasch C, Weber RS. Concurrent chemoradiation for adenoid cystic carcinoma of the head and neck. Head Neck 2012;34:1263-8.

31. Hosal AS, Fan C, Barnes L, Myers EN. Salivary duct carcinoma. Otolaryngol Head Neck Surg 2003;129:720-5.

32. Vander Poorten VL, Balm AJ, Hilgers FJ, Tan IB, Keus RB, Hart AA. Stage as major long term outcome predictor in minor salivary gland carcinoma. Cancer 2000;89:1195-204.

33. Tanvetyanon T, Qin D, Padhya T, McCaffrey J, Zhu

Cite this article as: Zang S, Chen M, Huang H, Zhu X, Li X, Yan D, Yan S. Oncological outcomes of patients with salivary gland cancer treated with surgery and postoperative intensitymodulated radiotherapy: a retrospective cohort study. Quant Imaging Med Surg 2022;12(5):2841-2854. doi: 10.21037/qims21-836
W, Boulware D, DeConti R, Trotti A. Outcomes of postoperative concurrent chemoradiotherapy for locally advanced major salivary gland carcinoma. Arch Otolaryngol Head Neck Surg 2009;135:687-92.

34. Maruya S, Namba A, Matsubara A, Kakehata S, Takeda I, Shirasaki T, Hatayama Y, Nagahata M, Yokoyama J, Shinkawa H. Salivary gland carcinoma treated with concomitant chemoradiation with intraarterial cisplatin and docetaxel. Int J Clin Oncol 2006;11:403-6.

35. Hsieh CE, Lin CY, Lee LY, Yang LY, Wang CC, Wang HM, Chang JT, Fan KH, Liao CT, Yen TC, Fang $\mathrm{KH}$, Tsang YM. Adding concurrent chemotherapy to postoperative radiotherapy improves locoregional control but Not overall survival in patients with salivary gland adenoid cystic carcinoma-a propensity score matched study. Radiat Oncol 2016;11:47.

36. Schoenfeld JD, Sher DJ, Norris CM Jr, Haddad RI, Posner MR, Balboni TA, Tishler RB. Salivary gland tumors treated with adjuvant intensity-modulated radiotherapy with or without concurrent chemotherapy. Int J Radiat Oncol Biol Phys 2012;82:308-14.

37. Tanvetyanon T, Fisher K, Caudell J, Otto K, Padhya T, Trotti A. Adjuvant chemoradiotherapy versus with radiotherapy alone for locally advanced salivary gland carcinoma among older patients. Head Neck 2016;38:863-70. 


\section{Supplementary}

Table S1 UVA and MVA for LRRFS and DMFS

\begin{tabular}{|c|c|c|c|c|c|c|c|c|c|c|c|c|c|}
\hline \multirow{3}{*}{ Variables } & \multirow{3}{*}{ Number } & \multicolumn{6}{|c|}{ LRRFS } & \multicolumn{6}{|c|}{ DMFS } \\
\hline & & \multirow{2}{*}{$\begin{array}{c}\text { At } 5 \text { years } \\
(\%)\end{array}$} & \multirow{2}{*}{$\begin{array}{c}\text { UVA } \\
\text { P value }\end{array}$} & \multicolumn{4}{|c|}{ MVA } & \multirow{2}{*}{$\begin{array}{c}\text { At } 5 \text { years } \\
(\%)\end{array}$} & \multirow{2}{*}{$\frac{\text { UVA }}{P \text { value }}$} & \multicolumn{4}{|c|}{ MVA } \\
\hline & & & & $\mathrm{HR}$ & AR & $95 \% \mathrm{Cl}$ & $P$ value & & & $\mathrm{HR}$ & AR & $95 \% \mathrm{Cl}$ & $P$ value \\
\hline Gender & & & 0.159 & & & & & & 0.06 & & & & \\
\hline Male & 35 & 74.8 & & & & & & 71.8 & & & & & \\
\hline Female & 25 & 91.5 & & & & & & 87.1 & & & & & \\
\hline Age (years) & & & 0.222 & & & & & & 0.485 & & & & \\
\hline$\leq 52$ & 31 & 88.4 & & & & & & 75.7 & & & & & \\
\hline$>52$ & 29 & 74.8 & & & & & & 80.5 & & & & & \\
\hline $\begin{array}{l}\text { Perineural } \\
\text { invasion }\end{array}$ & & & 0.601 & & & & & & 0.676 & & & & \\
\hline No & 41 & 80.9 & & & & & & 81 & & & & & \\
\hline Yes & 19 & 88.9 & & & & & & 76.7 & & & & & \\
\hline $\begin{array}{l}\text { Major never } \\
\text { involvement }\end{array}$ & & & 0.215 & & & & & & 0.024 & 2.115 & 21.1 & $0.521-8.583$ & 0.008 \\
\hline Negative & 32 & 89.5 & & & & & & 89.3 & & & & & \\
\hline Positive & 28 & 74.5 & & & & & & 68.2 & & & & & \\
\hline $\begin{array}{l}\text { Extra- } \\
\text { parenchymal } \\
\text { extension }\end{array}$ & & & 0.84 & & & & & & 0.476 & & & & \\
\hline No & 26 & 82.4 & & & & & & 83.8 & & & & & \\
\hline Yes & 34 & 84.2 & & & & & & 77.3 & & & & & \\
\hline Primary site & & & 0.591 & & & & & & 0.762 & & & & \\
\hline Parotid gland & 34 & 82.5 & & & & & & 79.4 & & & & & \\
\hline $\begin{array}{l}\text { Submandibular } \\
\text { gland }\end{array}$ & 17 & 75.3 & & & & & & 68.8 & & & & & \\
\hline $\begin{array}{l}\text { Sublingual } \\
\text { gland }\end{array}$ & 9 & 88.9 & & & & & & 74.1 & & & & & \\
\hline T stage & & & 0.337 & & & & & & 0.13 & & & & \\
\hline T1-T2 & 14 & 85.7 & & & & & & 92.3 & & & & & \\
\hline T3-T4b & 46 & 80.9 & & & & & & 74.7 & & & & & \\
\hline $\mathrm{N}$ stage & & & 0.173 & & & & & & 0.014 & & & & \\
\hline No & 41 & 83.7 & & & & & & 86.1 & & & & & \\
\hline N1 & 8 & - & & & & & & - & & & & & \\
\hline $\mathrm{N} 2 \mathrm{~b}$ & 8 & - & & & & & & 60 & & & & & \\
\hline N2c & 3 & - & & & & & & - & & & & & \\
\hline Clinical stage & & & 0.495 & & & & & & 0.049 & & & & \\
\hline I-II & 11 & 85.7 & & & & & & 100 & & & & & \\
\hline III-IVb & 49 & 82 & & & & & & 73.8 & & & & & \\
\hline Margin & & & 0.029 & 5.064 & 28.81 & $.211-21.187$ & 0.026 & & 0.055 & 6.367 & 24.8 & $1.524-26.603$ & 0.011 \\
\hline Positive & 53 & 85.9 & & & & & & 81.9 & & & & & \\
\hline Negative & 7 & 57.1 & & & & & & 57.1 & & & & & \\
\hline Skin involvement & & & 0.136 & & & & & & 0.932 & & & & \\
\hline No & 55 & 85.8 & & & & & & 78.3 & & & & & \\
\hline Yes & 5 & 40 & & & & & & 80 & & & & & \\
\hline $\begin{array}{l}\text { Interval from surge } \\
\text { (days) }\end{array}$ & ery to RT & & 0.239 & & & & & & 0.157 & 6.231 & 12.5 & $1.503-25.829$ & 0.012 \\
\hline$\leq 30$ & 30 & 88.9 & & & & & & 84.4 & & & & & \\
\hline$>30$ & 30 & 75 & & & & & & 71.9 & & & & & \\
\hline
\end{tabular}

P was calculated using log-rank test. UVA, univariable analysis; MVA, multivariable analysis; LRRFS, locoregional relapse-free survival; DMFS, distant metastasis-free survival; HR, hazard ratio; AR, absolute risk; $\mathrm{Cl}$, confidence interval. 